Session 3425

\title{
Writing in the Engineering Design Lab: How Problem Based Learning provides a Context for Student Writing
}

\author{
D.M. Douglas, C.R. Johnston, D.J. Caswell, M. Eggermont \\ Faculty of Engineering \\ University of Calgary
}

\begin{abstract}
It is the experience of most writing instructors that when students write (or speak) about subjects that matter to them many writing problems, such as grammar and poor organization, fall away. Since the quality of student writing seems to be dependant on the writing context, it is worthwhile looking at the situations in which we ask students to write.

If communication assignments are imposed by instructors to fulfill technical writing course requirements, the results are often predictably discouraging. Better writing is usually achieved if students generate written documents in order to communicate their own research. Problem-based learning, because it engages students in the real problems of their discipline, provides a necessary, rather than arbitrary, context for writing and oral presentation.
\end{abstract}

\section{Introduction}

When students write documents to communicate with real clients, they are motivated to write well in order to convey their design ideas beyond the university setting. Real projects, particularly with real clients, provide an ideal context in which to imbed meaningful communication assignments. In the University of Calgary first year engineering design lab, 600 students "get physical fast"1 and begin working on real world design problems from the first day of term.

Professional documents such as logbooks, contracts and status reports have as much utility in the classroom as they have in the workplace. Team discussion through on-line discussion boards and internal documents such as memorandum introduces students to typical workplace practice and to standard workplace formats. Client based documents such as progress reports and proposals introduce students to professional reporting conventions. 
The benefits of integrating communication assignments into a 600 student problem-based design lab include the opportunity for students to learn from the experience and example of other students and from collaboration with real world clients.

\section{Institutional Context}

The Boyer Commission's Report of 1998 called for a restructuring of undergraduate education at large research institutions. The report emphasized interdisciplinarity, undergraduate participation in research and the integration of communication skills into course work across the curriculum. At the University of Calgary the recommendations of the Boyer were taken up by the Undergraduate Curriculum Redesign Team. The team's final report, released in May 2003, called for a hands-on, inquiry-based approach to learning, particularly for first year students. Further, the Canadian Engineering Accreditation Board stipulates that every student must have real world, team-oriented, open-ended design experience before graduation.

Engineering 251/253 (ENGG 251/253), a collaboration between the faculties of art, engineering and communication, is an interdisciplinary first year engineering design course. It was first implemented in the 2002/2003 academic year in response to these challenges to innovate. The course was also designed to address student retention, a widespread concern among university engineering departments and a topic well discussed in the 2001 ASEE conference ${ }^{2,3}$. The curriculum of the course was built around four pillars: drawing, design, communication and teamwork.

\section{The Engineering Design Lab}

The University of Calgary invested 1.28 million dollars as a start up contribution to the design and construction of four technologically advanced laboratories for the first year design course. The four linked labs circle around a central broadcast booth; instructors can broadcast to all labs simultaneously and are able to monitor lab activities through feedback screens. The four labs accommodate 150 students at one time; students work at lab tables in teams of four. Each lab has a document camera, a projection screen, a computer terminal for every two students, and a complete tool box for each two lab tables.

Instructors meet with students for a one hour lecture each week. Labs are four and half hours a week. Student-faculty contact is facilitated by Blackboard, an interactive online source of course information and venue for course discussion.

\section{Course Structure}

ENGG 251/253 is designed and coordinated by four faculty members: two from the Faculty of Engineering, one from the Faculty of Communication and Culture, and one from the Faculty of Fine Arts. Labs are run by a team of coaches, graduate students from each of the three participating disciplines. An instructional team this size allows

extensive faculty-student contact which has a significant impact on student satisfaction ${ }^{4}$. 
Four linked labs run concurrently so that coaches from each discipline are available to all teams at all times ( 1 drawing coach, 1 communication coach, 2 engineering coaches).

The course presents students with real world, open-ended problems requiring students to access their own experience and intellectual resources and to apply the engineering knowledge learned in other courses. In the 2003/2004 academic year, the real world clients included Engineers Without Borders, the Olympic Oval, and a Calgary based biomedical company (creating design ideas for an operating table clamp to hold limbs during surgery). Student projects varied from six weeks (designing crash pad protection for outdoor amateur skating ovals) to two weeks (developing ideas for water filtration and waste management for a village in India).

The course is problem-based in its structure and inquiry-based in its emphasis on investigation, questioning and learning through experience.

\section{Communication Assignments in the Design Lab}

Practicing engineers do not receive grammar quizzes or essay topics from their bosses. They write reports and proposals and make presentations to other professionals and to clients. The technical nature of engineering, and the financial and legal consequences of the work, means that graduating engineers probably require stronger communication skills than most graduating students ${ }^{5}$. To train students for writing in the engineering profession, assignments should reflect the nature of the work. Problem-based engineering courses require workplace types of communication - progress reports, proposals, oral reports, presentations. Engineering graduates must be able to establish relationships with co-workers and clients, they must have questioning skills in order to determine the parameters of engineering problems and to test developing designs, and they must be able to convey technical information clearly to both colleagues and clients.

In modeling actual engineering communication requirements, students become aware of the expectations and reporting conventions of their profession. The nine deliverables of the project reflect common engineering practice:

- Engineering Logbook

- Team contract

- Annotated bibliography

- Progress Report: Familiarization, Preliminary Design development

- Progress Report: Testing results

- Progress Report: Design Modifications

- Final Report: Design Proposal

- Oral presentation based on progress reports

- Memo to Coaches re performance evaluation

The crash pad project was evaluated on the justification and testing of the design as communicated in written documents and oral presentations. Student grades for the project were dependent not on the design itself but on the design process and student's abilities to defend their design decisions with verifiable data. 
The faculty's engineer in residence who comes to us from industry points out that failures in engineering projects are often failures in communication. The classic example of this is the Challenger disaster. According to the investigation committee's report, one of the reasons why the O-ring problem was not fully appreciated by the NASA team was poor communication, particularly important data presented in unclear visual displays ${ }^{6}$. This example highlights the importance of including effective communication in engineering education.

Communication assignments integrated into engineering design projects not only introduce students to professional standards of communication, they serve a practical purpose in the design lab.

- Team contracts help students clarify roles, assign responsibilities, establish common team goals, and define procedures for dealing with team conflict before conflict arises. Students can also negotiate the grades each team member expects and the commitment each is willing to make toward the final grade. Instructors will honor the distribution of grades established within the team.

- Engineering logbooks develop student awareness of the professional need to track the development of ideas, to record meetings and information about the project and to document the time and date of work accomplished. Students use logbooks to

○ document design ideas

- sketch design prototypes

$\bigcirc$ track project status and work assigned

o record team decisions

o document team conflict

- note ideas \& references of good design

$\circ$ integrate information from other courses

- Informal project status reports, recorded in logbooks, help students manage time and meet deadlines.

- Milestone reports require that students document the progress of their designs and help keep the project moving to meet scheduled deliverables.

- Oral reports at milestone stages of design alert all teams to divergent design ideas and allow them to compare their own design with those of their classmates.

\section{The Writing Process Corroborates Engineering Design}

The engineering design process is introduced to first year engineering students as a process of questioning focusing on three key principles: familiarization, function and testing, referred to as the design trinity ${ }^{7}$.

Students begin the design process by familiarizing themselves with the problem through observation and fact finding. At this early stage they test their own understanding of the problem and question clients involved. Out of these initial probes, they begin to define the key functions the ultimate design must perform. As initial design ideas begin to emerge, students continue to define their design criteria and to develop tests for 
performance. Continuous testing increases familiarization and understanding of functionality which drives design modification (Fig. 1).

Like engineering design, the writing process is iterative: as the document develops the writer becomes increasingly more familiar with the requirements of the text.

The basic principles of composition were first codified by Aristotle in The Rhetoric in 500 B.C.E., and, explicitly or implicitly, they have been a component of most writing texts since then. While The Rhetoric was written as a guide to effective oratory, it can also be seen as the first treatise on design. The Rhetoric lays out the basic stages common to any design process: analyzing the situation, defining a problem, generating a range of possible solutions, selecting the most appropriate solution given the situation, organizing information and ideas to suit the intended purpose and the intended user. The rhetorical process, like the design process, imbeds continuous revision and modification. In this way, the rhetorical process parallels the engineering design process.

Most writing texts stress the initial stages of composition: understanding the needs and expectations of the audience and identifying the purpose of the discourse. Questioning what the audience wants (or think they want) is as fundamental to communication as understanding the needs of the client is to engineering design. Defining the purpose of the discourse in order to choose the most appropriate arguments and supporting evidence is to composition what defining function is to design. The writing process and the design process corroborate one another, making the engineering design lab a particularly responsive environment in which to introduce the basic principles of clear communication (Table 1).

Table 1: Comparison of the Writing and the Design Process

\begin{tabular}{|l|l|l|}
\hline The Design Process & The Writing Process & \multicolumn{1}{c|}{ Stages of the Process } \\
\hline Familiarization & $\begin{array}{l}\text { Analyze the Rhetorical } \\
\text { Situation }\end{array}$ & $\begin{array}{l}\text { Assess audience \& purpose. } \\
\text { Establish the criteria for the design/ document. } \\
\text { Who is the client/ audience? What is the purpose? }\end{array}$ \\
\hline Functionality & $\begin{array}{l}\text { Invention \& } \\
\text { Arrangement }\end{array}$ & $\begin{array}{l}\text { Generate \& select ideas. } \\
\text { Establish key criteria for the design/ document. } \\
\text { Develop designs/ arguments/ ideas. }\end{array}$ \\
\hline Testing & Revision & $\begin{array}{l}\text { Justify/ support arguments/ claims/ solutions. } \\
\text { Revise and modify as design/ document develops. }\end{array}$ \\
\hline
\end{tabular}

Proceedings of the 2004 American Society for Engineering Education Annual Conference \& Exposition Copyright (C2004, American Society for Engineering Education 


\section{Grading Assignments and 'Re-do' policy}

Student work in the engineering lab is graded to reflect workplace standards. Engineering companies do not award letter grades. Sometimes design work is excellent; sometimes it is merely good but strong enough to proceed with the project; sometimes it needs revision before the project can go ahead. Correspondingly, student assignments receive stamps of excellent, good or 're-do'. Instructors then post samples of all levels of student work, annotated with instructor comments, in display cabinets outside the lab and electronically on Blackboard. All student teams can compare their work to the work of their peers. The 're-do' policy offers students the opportunity to strengthen their work before they resubmit.

We have found that with this opportunity to learn from the work of others, student reporting improves steadily over the term. The initial reports of each first term focus on content but are poor in document design. Over the course of the term students begin to adopt professional formatting conventions, to use correct engineering reference citation and to communicate their ideas visually through tables, sketches and drawings. The final assignments of the 2003 fall term, proposals for crash pad designs, included concise executive summaries, clear organization of information, good presentation of data in charts and graphs, illustrative drawings and sketches and solid justification of each stage of the team's solution path.

A 600 student class presents some challenges in developing a writing curriculum but in the first year design course, numbers have proved a distinct advantage. Students learn best from the example of others.

\section{The Classic Student Dilemma in Writing}

The typical university classroom writing situation asks students to write as if they were writing for a client or a boss. In reality, students are writing for a grade-giving instructor, and they know it. This sets them up for the classic student dilemma: being required to write for one audience, an imagined 'client' who has a certain knowledge of the subject and expectation of the text, while at the same time accommodating a second audience, the instructor who has a different, and often more complete, knowledge of the subject $^{8}$.

A real-world writing situation involves the writer (engineer) producing a text about a project for a specific audience (client). The writer has a clear idea, or can find out, what the audience already knows about the Subject

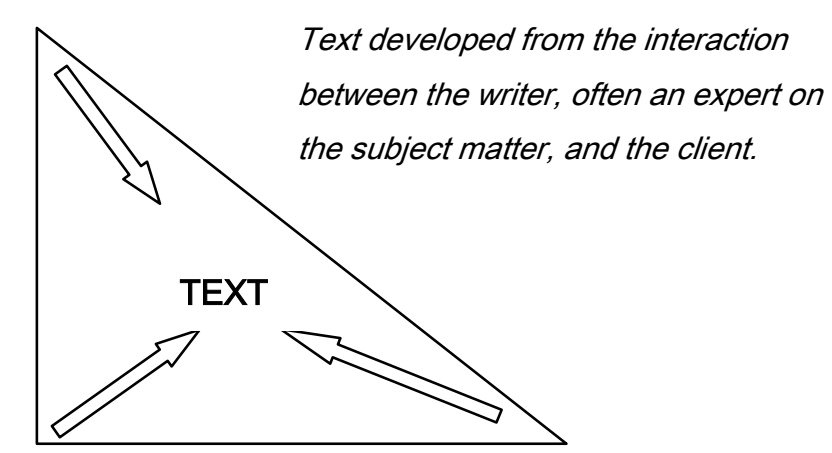
subject or problem and what the audience needs to know in order to understand or

Writer Client

Figure 2: Typical Real World Writing Situation 
accept the design ideas presented. The resulting text is clearly embedded in the working situation.

In the university classroom or lab, the author has a second audience, the instructor. This audience, although supposedly invisible, has a whole different set of expectations of the text. He or she does not look for the same criteria a client would or looks for criteria in addition to what a client might expect. The student writer ends up looking two ways trying to accommodate both audiences (Fig. 3).

\section{Subject}

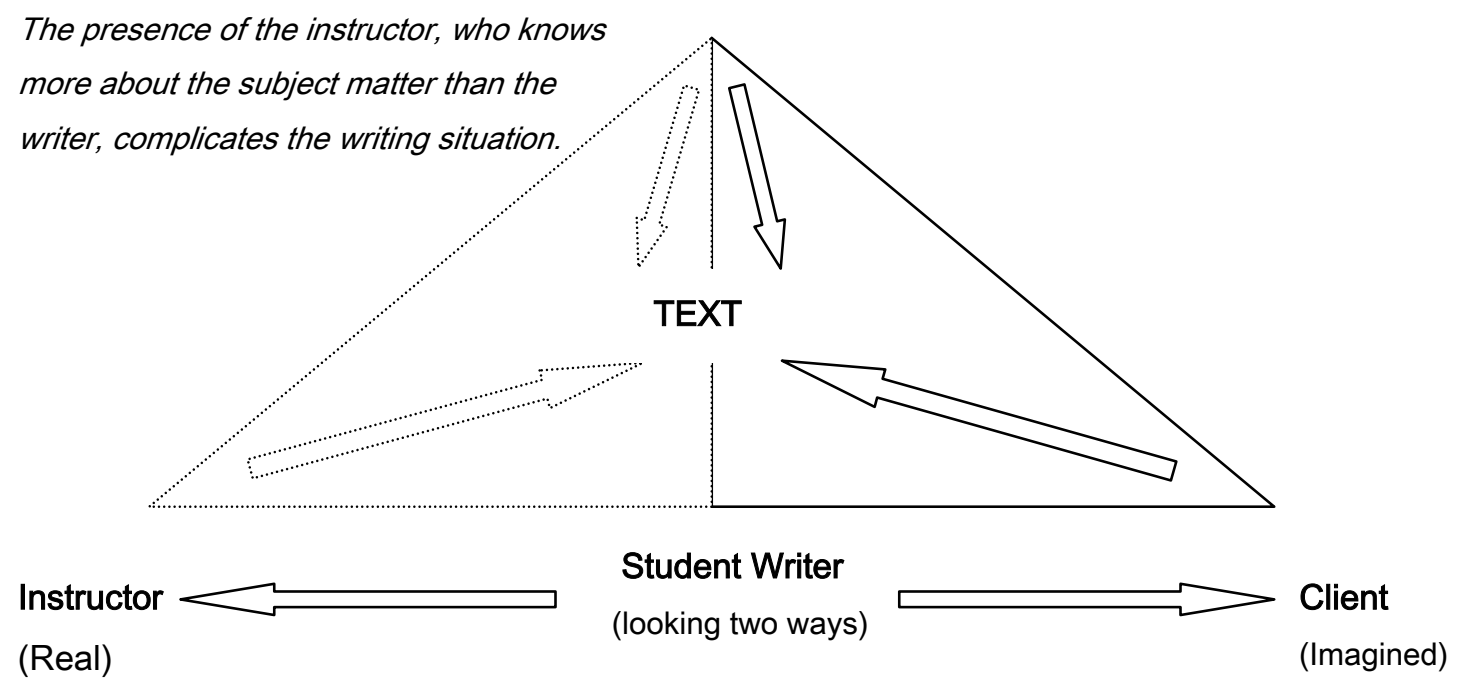

Figure 3: Typical classroom writing situation

The writing purpose in the workplace derives from the real need to communicate the status of the organization's work; in the classroom, the purpose of writing is often the evaluation of the writing itself. In the workplace, writers work within the context of the organization. Genres (eg., letter, memo, instruction, report) and formats are flexible and designed to meet specific communication requirements. In the classroom, genres and formats are treated as inflexible and the writing is imbedded in no real organizational context. Students see the requirements of the writing task as arbitrary if writing is assigned as a means to assess writing skill rather than as a means to communicate project information.

In problem-based learning environments such as an engineering design lab, especially if students are working on real world problems and if communication assignments are imbedded in design projects, the inherent problems of the student writer are somewhat diminished. Students who develop ideas in conjunction with, and with feedback from, real clients are motivated to write clear and coherent reports. While it remains true that instructors usually grade these reports, students see instructors as a secondary audience for the text. 
We noticed a falling off of writing motivation in the second term when students were writing milestone reports on the development of a skating robot. The audience for the milestone reports was coaches. When the students knew the reports would not be forwarded to clients, the quality of the reporting decreased.

Students working in problem-based learning environments, either with real clients or designing for competitions, are usually highly engaged in their projects. This enhances their motivation to communicate design decisions and results as effectively as possible, especially if they know their work might be forwarded to the client. In itself, this is no guarantee of strong writing, but because students are motivated to succeed, they listen carefully to instruction and suggestion about writing when it is offered.

\section{Student Motivation in Writing}

The work of Raymond Wlodkowski explains student motivation to write well in contexts in which they are engaged ${ }^{9}$. Wlodkowski sees student motivation to succeed as a product of two factors: the value they place on the tasks they are asked to perform and their expectation of performing well. To be motivated, both need to be in place. If either of these factors is missing, student motivation decreases.

When students don't see the point of writing assignments, they place little value on the work. Even if they are capable and confident of success, their motivation to apply themselves will be low. In comparison, if students are engaged in projects and if they see that communication is integral to the success of the project, they will value written assignments associated with the project more highly. In this case, even if they have only a moderate expectation of success, their motivation to produce effective documents will be higher.

Documents produced by first year students in the Engineering Design course at the University of Calgary demonstrate Wlodkowski's theory. The hands-on nature of the work increases the value they place on communication assignments. Instruction, instructor feedback, and posted examples of the work of their peers increase their expectation of success.

The first project reports this year were proposals to provide power and clean water to a village in India for Engineers Without Borders. The student arm of Engineers Without Borders coordinated the project and outlined the deliverables of the assignment. Writing instructions were not clear. As a result, even the strongest reports lacked adherence to standard reporting conventions. The reports read like the essays you might expect from seventeen and eighteen year olds just out of high school. Although the students valued the project highly, they had not been given the tools for successful report writing. Later in the term, when introduced to the formatting conventions of engineering and standard ways of organizing their material under appropriate headings, student reports improved dramatically. 


\section{Benefits of Integrating Writing into the Engineering Curriculum}

Integrating writing assignments into engineering design projects has benefits beyond developing students' professional communication skills. It also provides students with the opportunity to improve their design skills by

- Learning team-building skills, including leadership and follower roles, the art of compromise and the ability to schedule and manage the efforts of several individuals,

- Acquiring practice in communicating with non-engineers,

- Encountering and resolving difficult to predict communication problems both among colleagues and with clients,

- Analyzing and developing solutions for ill-defined real world problems,

- Preparing for a range of communication situations in the future.

\section{Conclusion}

It is our experience that setting first year communication assignments in the context of meaningful research enhances student motivation to produce clear, well organized documents and oral presentations. Traditional technical writing exercises do not achieve the same results.

Imbedding writing assignments in design projects works on two levels:

- Familiarizing students with professional engineering documents

- Increasing student motivation to communicate effectively by moving the communication focus from the classroom to the real world

Engineering faculties face understandable difficulties in imbedding writing across the curriculum given the overwhelming amount of technical information students must acquire before they graduate. But integrating communication skills into the engineering curriculum is a worthwhile goal. When we achieve it, we will be offering our students competency in one of the key requirements for success in their careers.

\section{References}

1. Corporate Design Foundation, "Chapter 4: Assessing Progress", Teaching Collaborative Product Development. [Online] Available: http://www.cdf.org/frameset.html [March 5, 2004]

2. Roth, Ronald. "Improving Freshman Retention Through an Introduction to Engineering Design Course." Proceedings of the 2001 American Society for Engineering Education Annual Conference \& Exposition. June 2001.

3. Wood, J.C. et. al. "Problem-Based Learning and Interdisciplinary Instruction." Proceedings of the 2001 American Society for Engineering Education Annual Conference \& Exposition. June 2001.

4. Umbach, Paul D., Porter, Stephen R. "How do Academic departments impact student satisfaction? Understanding the Contextual Effects of Departments." Research in Higher Education 43(2), 2002, pp.209-234.

5. Patton, Martha D. et. al. "Dealing with Resistance to WAC in the Natural and Applied Sciences." [Online] Available: wac.colostate.edu/llad/v3nl.patton.pdf. [Sept. 20, 2003]

6. Tufte, Edward R. Visual Explanations: Images and Quantities, Evidence and Narrative. Cheshire, Connecticut: Graphics Press 1997, pp. 39-53. 
7. Caswell, D.J. et. al. "Fundamentals of a First-Year Engineering Design and Communication Course: Familiarization, Functionality and Testing." Proceedings of the 2004 American Society for Engineering Education Annual Conference \& Exposition. June 2004.

8. Andre, J. et. al. "Writing: Making it form the Classroom to the Real World," presented at the STLHE conference, Vancouver, British Columbia, 1994.

9. Wlodkowski, R.J. "Strategies to Enhance Adult Motivation to Learn", Adult Learning Methods. M.W. Galbraith (ed.). Malabar, FL: Kreiger Publishing, 1989, pp. 76 - 86. 